\title{
Anti-inflammatory and antioxidant effects of mesenchymal and hematopoietic stem cells in a rheumatoid arthritis rat model
}

\author{
Hanan Abdelmawgoud ${ }^{A-F}$, Asmaa Saleh ${ }^{A-F}$ \\ Department of Biochemistry, Faculty of Pharmacy, Al-Azhar University, Cairo, Egypt \\ A - research concept and design; $\mathrm{B}$ - collection and/or assembly of data; $\mathrm{C}$ - data analysis and interpretation; \\ $D$ - writing the article; $E$ - critical revision of the article; $F$ - final approval of the article
}

Address for correspondence

Hannan Abdelmawgoud

E-mail: hananmoawad@gmail.com

Funding sources

None declared

Conflict of interest

None declared

Received on March 15, 2017

Reviewed on April 25, 2017

Accepted on May 14, 2017

\begin{abstract}
Background. Mesenchymal stem cells (MSCs) are of increased importance because of their capacity to counteract inflammation and suppress host immune responses.

Objectives. The aim of the study was to compare the effectiveness of MSCs and hematopoietic stem cells (HSCs) in the treatment of rheumatoid arthritis (RA).

Material and methods. Paw swelling was assessed by measuring the thickness of the hind paws using a caliper. Cytokines - interleukin (IL)-6, tumor necrosis factor-alpha (TNF-a), transforming growth factor-beta (TGF- $\beta$ ), and IL-10 - and rheumatoid factor (RF) were measured using enzyme-linked immunosorbent assay (ELISA) kits. Oxidative stress biomarkers - malondialdehyde (MDA) and reduced glutathione (GSH) were assessed. Nuclear factor-kappaB (NF-KB) was detected by the western blot technique. Toll-like receptor-2 (TLR-2), matrix metalloproteinase-3 (MMP-3) and cartilage oligomeric matrix protein-1 (COMP-1) gene expression were assessed by the real-time quantitative analysis. Mesenchymal stem cells were isolated from the bone marrow (BM) of rats and HSCS were isolated from human umbilical cord blood (UCB).
\end{abstract}

Results. Paw edema, RA score, RF, cytokine assay, antioxidant state, NF-KB, TLR-2, MMP3, and COMP-1 showed improvement in the group that received MSCs compared to the group that received HSCS and the group that received methotrexate.

Conclusions. Mesenchymal stem cells are very effective in reducing RA inflammation; they are superior to HSC and methotrexate treatment. Mesenchymal stem cells could become a better therapeutic opportunity for the treatment of RA.

Key words: methotrexate, rheumatoid arthritis, mesenchymal stem cells, hematopoietic stem cells

DOI

10.17219/acem/73720

\section{Copyright}

Copyright by Author(s)

This is an article distributed under the terms of the

Creative Commons Attribution Non-Commercial License

(http://creativecommons.org/licenses/by-nc-nd/4.0/) 


\section{Introduction}

Rheumatoid arthritis (RA) is a systemic autoimmune disease that basically affects the joints and is influenced by hereditary and environmental factors. ${ }^{1}$ Patients with RA have short lifespans due to comorbidities. Inflammation plays a vital role in the development of cardiovascular disease; however, little is known about its association with other comorbidities. ${ }^{2}$ In the pathophysiology of RA, there is interaction between T cells, B cells and some cytokines. Pro-inflammatory cytokines have not only articular effects, but also systemic effects, like acute-phase protein production, cardiovascular disease, osteoporosis, and anemia. $^{3}$

Tumor necrosis factor-alpha (TNF- $\alpha$ ) plays an important role in the regulation of the production of other pro-inflammatory cytokines in rheumatic synovial tissue. ${ }^{4}$ Interleukin (IL)-4, IL-10 and IL-13 are anti-inflammatory cytokines that compensate for the action of pro-inflammatory cytokines in the synovial membrane in RA. Transforming growth factor-beta (TGF- $\beta$ ) is a pleiotropic cytokine that has different functions in angiogenesis, hematopoiesis, cell proliferation, differentiation, migration, and apoptosis. As Gonzalo-Gil and Galindo-Izquierdo wrote: „Although its role in rheumatoid arthritis is not well defined, the TGF- $\beta$ activation leads to functional immunomodulatory effects according to environmental conditions." 5

In the synovial cells of RA patients, the stimulation of the nuclear factor-kappaB $(N F-\kappa B)$ pathway leads to the transactivation of a lot of responsive genes that result in the inflammatory phenotype, including matrix metalloproteinases (MMPs) from synovial fibroblasts, TNF- $\alpha$ from macrophages and chemokines that deliver immune cells to the inflamed pannus. ${ }^{6}$

Toll-like receptors (TLRs) are expressed by the cells inside the RA joint, and there is a group of endogenous TLR ligands in the inflamed joints of RA patients. The activation by these ligands may result in the continuous expression of pro-inflammatory cytokines by macrophages and the joint damage that takes place in RA. This supports a possible role for the TLR signalling suppression as a new curative line in RA. ${ }^{7}$

Measurement of biological markers for cartilage degradation and repair would be a useful approach in RA monitoring. Cartilage oligomeric matrix protein (COMP) is one of the arthritis markers that is released into the synovial fluid and other body fluids, like blood. In several studies, COMP has been used as a diagnostic and prognostic marker of disease severity and the effect of treatment. ${ }^{8}$ Cartilage oligomeric matrix protein binds to many extracellular matrix proteins, and other proteins, like MMPs, are known to regulate the levels of COMP under different conditions. ${ }^{9}$

Methotrexate is the most frequently used treatment in RA. For most RA patients, it is suggested as the first disease-modifying anti-rheumatic drug (DMARD), and its co-prescription is recommended with biologic DMARDs. ${ }^{10,11}$ Due to the side effects and high cost of these medications, it is important to develop a new and more effective therapy for RA.

Mesenchymal stem cells (MSCs) exist in all tissues as multipotent adult stem cells that can differentiate into various tissues, arising from mesoderm-like cartilage, bone and cardiac muscle. Mesenchymal stem cells are very effective in cell therapy because of their easy access, straightforward isolation and their bio-preservation with minimal loss of potency. Therefore, MSCs are being examined to regenerate injured tissue and cure inflammation. ${ }^{12}$

Mesenchymal stem cells can be used to adjust autoimmune responses and in autoimmune disease treatment, because they cause immunosuppression by modulating $\mathrm{T}$ and $\mathrm{B}$ cell proliferation and differentiation, dendritic cell growth and the activity of natural killer cells. ${ }^{13}$ Mesenchymal stem cells can differentiate to several cell lineages, such as osteoblasts and chondrocytes. ${ }^{14}$ Furthermore, MSCs show high migration and motility, and can secrete cytokines to enhance the repair of damaged tissues; accordingly, MSCs have been used to treat many diseases in clinical trials. ${ }^{15}$ Mesenchymal stem cells are thought to be able to treat several congenital and acquired bone degenerative diseases, and to fix and regenerate injured bone tissues, contributing to better clinical results in skeletal tissue repair and regeneration. Mesenchymal stem cells can be transplanted by blending with autogenous plasma/serum or by packing onto repair/induction supportive resorbable structures. ${ }^{16}$

This study aimed to compare the effectiveness of MSCs and hematopoietic stem cells (HSCs) in the treatment of RA.

\section{Material and methods}

\section{Preparation of the animal model}

The study was carried out on 40 male Wistar rats (average weight: $150-200 \mathrm{~g}$ ). All the ethical protocols for animal treatment were followed and supervised by the animal facilities at the Faculty of Medicine of Cairo University (Egypt). The rats were divided into 5 groups of 8 animals each. Group 1 was the negative control (NC) group, and received $1 \mathrm{~mL}$ saline by intravenous injection. Group 2 was the positive control (PC), in which arthritis was induced by injecting each rat with $0.1 \mathrm{~mL}$ of complete Freund's adjuvant (CFA) (Sigma-Aldrich, St. Louis, USA), producing definite edema within $24 \mathrm{~h}$, with progressive arthritis by day 9 after inoculation. ${ }^{17}$ Treatments were initiated from day 10 and continued through day 37. Group 3 (MTX) comprised arthritis rats that received $2 \mathrm{mg} / \mathrm{kg}$ of methotrexate (MTX) once a week for 4 weeks. ${ }^{18}$ Group 4 (MSC) comprised arthritis rats that received MSCs in a single intravenous dose in the form of a cell suspension containing $10^{6}$ allogeneic MSCs derived from the bone marrow (BM) 
of rats. Group 5 (HSC) was composed of arthritis rats that received HSCs in a single intravenous dose in the form of a cell suspension containing $10^{6}$ allogeneic HSCs derived from human umbilical cord blood (UCB). ${ }^{19}$

\section{Isolation and culture of bone marrow mesenchymal stem cells}

Bone marrow was harvested by flushing the tibiae and femurs of rats with Dulbecco's modified Eagle's medium (DMEM) (Lonza Bioscience, Verviers, Belgium) supplemented with $10 \%$ fetal bovine serum. Nucleated cells were isolated with a density gradient (Ficoll-Paque; Gibco-Invitrogen, Grand Island, USA). This mononuclear layer was aspirated, washed twice in phosphate-buffered saline (PBS) containing $2 \mathrm{mM}$ of ethylenediaminetetraacetic acid (EDTA) and centrifuged for $10 \mathrm{~min}$ at $200 \times \mathrm{g}$ at $10^{\circ} \mathrm{C}$, and re-suspended in complete culture medium supplemented with $1 \%$ penicillin-streptomycin. The cells were incubated at $37^{\circ} \mathrm{C}$ in $5 \% \mathrm{CO}_{2}$ for 14 days. When large colonies developed (80-90\% confluence), the cultures were washed twice with PBS and the cells were trypsinized with $0.25 \%$ trypsin in $1 \mathrm{mM}$ EDTA for $5 \mathrm{~min}$ at $37^{\circ} \mathrm{C}$. After centrifugation, the cells were re-suspended in serum-supplemented medium and incubated in Falcon ${ }^{\circledR}$ tissue culture flasks. The cultured MSCs were confirmed by morphology and fluorescent analysis cell sorting (FACS), by detecting CD29+ve and CD34-ve specific to MSCs (Fig. 1). ${ }^{20}$

\section{Collection of human umbilical cord blood and isolation of hematopoietic stem cells}

Human umbilical cord blood was withdrawn immediately after normal vaginal delivery within $24 \mathrm{~h}$ of the rupture of the membranes and before the separation of the placenta. Written informed consent was obtained from each woman after a full explanation of the study. The umbilical cord was sterilized with $70 \%$ alcohol followed by betadine at the needle insertion site. As much bloodflow as possible was collected. Anti-coagulated UCB was diluted 1:4 with PBS containing 2 mM EDTA. Cord blood mononuclear cells (MNCs) were separated by centrifugation over FicollPaque (Gibco-Invitrogen) at $400 \times \mathrm{g}$ for $35 \mathrm{~min}$ at $10^{\circ} \mathrm{C}$. The MNC fraction was washed first in PBS, then with magnetic cell sorting buffer (MACS: PBS supplemented with $0.5 \%$ bovine serum albumin and $2 \mathrm{mM}$ EDTA, pH 7.2). CD34+ cells were isolated from MNCs using a CD34+ positive cell selection kit (Mini-Macs; Miltenyi Biotec,
Bergisch Gladbach, Germany) according to the manufacturer's instructions. The percentage of isolated CD34+ cells was characterized by flow cytometry (Fig. 1 ). ${ }^{21}$

\section{Clinical scoring of paw edema}

Paw swelling was assessed by measuring the thickness of the hind paws using a caliper. Joint swelling was scored using an arthritis index. Briefly, a score of 0-4 was assigned, where 0 means there was no evidence of hyperemia and/or inflammation; 1 indicates hyperemia with little or no paw swelling; 2 represents swelling confined predominantly to the ankle region, with modest hyperemia; 3 indicates increased paw swelling and hyperemia of the ankle and metatarsal regions; and 4 indicates maximal paw swelling and hyperemia involving the ankle, metatarsal and tarsal regions.

\section{Biochemical measurement of rheumatoid factor, IL-6, IL-10, TNF- $\alpha$, and TGF- $\beta$}

Serum rheumatoid factor (RF) was determined using a QUANTA Lite enzyme-linked immunosorbent assay (ELISA) kit (Inova Diagnostics, San Diego, USA) according to the manufacturer's instructions. Serum IL-6, IL-10, TNF- $\alpha$, and TGF- $\beta$ were measured using Quantikine ELISA kits (R\&D Systems Inc., Minneapolis, USA) according to the manufacturer's instructions.

\section{Measurement of malondialdehyde}

Joint tissue was homogenized in $1 \mathrm{~mL}$ PBS, pH 7.0, with a micropestle in a microtube. Then $20 \%$ trichloroacetic acid (TCA) was added to the tissue homogenate to precipitate the protein, and the mixture was centrifuged. Supernatants were collected and the thiobarbituric acid (TBA) solution was added to them. After boiling for $10 \mathrm{~min}$ in a water bath, the absorbance of the clear supernatant was determined at $535 \mathrm{~nm}$. The concentration of malondialdehyde (MDA) was calculated using a series of standard solutions $(0,0.625,1.25,2.5,5.0$, and $10 \mathrm{nmol} / \mathrm{mL}){ }^{22}$

\section{Measurement of reduced glutathione}

Joint tissue was homogenized in PBS, $\mathrm{pH}$ 8.0, and then $5 \%$ TCA was added to the homogenate to precipitate the protein. After centrifugation, the dithiobisnitrobenzoate (DTNB) solution was added to the supernatants of the tissue homogenate, and they were incubated for $1 \mathrm{~h}$.
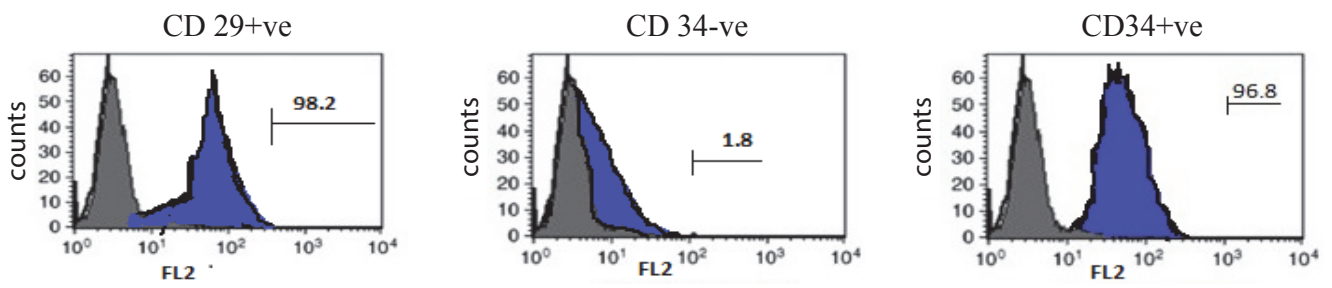

Fig. 1. Characterization of BMMSCs by CD 29+ve and CD 34-ve and characterization of HSCS by CD 34+ve

BM-MSCs - bone marrow mesenchymal stem cells; HSCS - hematopoietic stem cells. 
The absorbance was measured at $412 \mathrm{~nm}$. The concentration of reduced glutathione (GSH) was calculated using the standard curve with the following concentrations: 0 , $10,20,40,50$, and $100 \mathrm{mmol} / \mathrm{mL}^{23}$

\section{Real-time quantitative analysis for MMP-3, COMP-1 and TLR2 gene expression}

Total RNA was extracted from the joint tissue homogenate using the SV Total RNA Isolation System (Promega, Madison, USA) according to the manufacturer's instructions. Complementary DNA (cDNA) was synthesized from $1 \mu \mathrm{g}$ RNA using the SuperScript III First-Strand Synthesis System as described in the manufacturer's protocol (No. K1621, Fermentas, Waltham, USA). The real-time quantitative polymerase chain reaction (PCR) amplification and analysis were performed using a StepOne ${ }^{\mathrm{TM}}$ realtime quantitative PCR system with software v. 3.1 (Applied Biosystems, Thermo-Fisher Scientific Inc., Waltham, USA). The reaction contained a SYBR Green Master Mix (Applied Biosystems), gene-specific primer pairs designed with Gene Runner Software (Hasting Software Inc., Hasting, USA) from RNA sequences from GenBank. The data from the real-time assays were calculated using Sequence Detection Software v. 1.7 (PE Biosystems, Foster City, USA). The relative quantification (RQ) of the studied gene mRNA was calculated using the comparative $\mathrm{Ct}$ method. All values were normalized to $\beta$-actin, which was used as the control housekeeping gene, and were reported as fold changes over background levels detected in the disease groups.

\section{Detection of NF-KB by western blot technique}

Nuclear factor-kappaB was detected using a V3 Western Workflow ${ }^{\mathrm{TM}}$ Complete System (Bio-Rad Laboratories Inc., Hercules, USA). The protein was extracted from the tissue homogenates using the ice-cold radioimmunoprecipitation assay (RIPA). The lysis buffer PL005 (Bio BASIC Inc., Markham, Canada) consisting of $50 \mathrm{mM}$ Tris hydrochloride (Tris HCL), $150 \mathrm{mM}$ sodium chloride $(\mathrm{NaCl})$, $1 \%$ Triton $\mathrm{X}-100,1 \%$ sodium deoxycholate, and $0.1 \%$ sodium dodecyl sulfate (SDS) was supplemented with phosphatase and protease inhibitors, and then centrifuged at $12,000 \mathrm{rpm}$ for $20 \mathrm{~min}$ at $4^{\circ} \mathrm{C}$. The protein concentration for each sample was determined using the Bradford assay. Equal amounts of protein (20-30 $\mu \mathrm{g}$ of total protein) and the $2 \mathrm{X}$ Laemmli buffer were heated at $70^{\circ} \mathrm{C}$ for $5-10 \mathrm{~min}$ and separated by SDS/polyacrylamide gel electrophoresis (SDS-PAGE) using a Mini-Protein II system (Bio-Rad Laboratories Inc.). The protein was transferred to polyvinylidene difluoride (PVDF) membranes (Pierce Biotechnology Inc., Rockford, USA) with a TGX Stain-Free ${ }^{\mathrm{TM}}$ FastCast $^{\mathrm{TM}}$ Acrylamide Kit (Bio-Rad Laboratories Inc.). After the transfer, the membranes were washed with Tris-buffered saline (TBS) and blocked for $1 \mathrm{~h}$ at room temperature with $5 \%(\mathrm{w} / \mathrm{v})$ skimmed milk powder in TBS. The manufacturer's instructions were followed for the primary antibody reactions. Following the blocking, the blots were developed using antibodies for $N F-K B$ and $\beta$-actin (Thermo Fisher Scientific, Rockford, USA), incubated overnight at $\mathrm{pH} 7.6$ at $4^{\circ} \mathrm{C}$ with gentle shaking. After washing, peroxidase-labeled secondary antibodies were added, and the membranes were incubated at $37^{\circ} \mathrm{C}$ for $1 \mathrm{~h}$, then washed with TBS 5 times for 5 min. Clarity Western ECL chemiluminescent substrate (Bio-Rad Laboratories Inc.) was applied to the blot according to the manufacturer's recommendations. Band intensity was analyzed using a ChemiDoc ${ }^{\mathrm{TM}}$ imaging system with Image Lab ${ }^{\mathrm{TM}}$ software v. 5.1 (Bio-Rad Laboratories Inc.). The results were expressed as arbitrary units after normalization for $\beta$-actin protein expression.

\section{Statistical analysis}

The normality of data distribution was tested using the Shapiro-Wilk normality test. The analysis of normally distributed data was done by one-way analysis of variance (ANOVA), followed by Tukey's multiple comparison test (the data is expressed as mean with standard deviation - SD). For nonnormally distributed data, the Kruskal-Wallis test was used to compare the median of each group, followed by Dunn's multiple comparison test using Prism v. 5.03 software (GraphPad Software, La Jolla, USA). Statistical significance was set at $\mathrm{p}<0.05$.

\section{Results}

Paw edema was lower in the MTX group ( $3.37 \pm 0.65 \mathrm{~mm})$, the MSC group $(2.73 \pm 0.52 \mathrm{~mm})$ and the HSC group $(3.32 \pm 0.57 \mathrm{~mm})$ than in the PC group $(4.88 \pm 1.17 \mathrm{~mm})$, with p-values $<0.001,<0.0001$ and $<0.001$, respectively (Fig. 2A). The evaluation of the RA score indicated that the PC group showed the top score (median: 4, range: 3-4), which was significantly higher than that observed in the MTX group (median: 2, range: 1-2) with p-value $<0.05$ and in the MSC group (median: 1 , range: $1-2$ ) with p-value $<0.0001$ (Fig. $2 \mathrm{~B}$ ). There was no significant difference between the PC group and the HSC group (median: 2, range: $1-3$ ). There was also no significant difference between the MTX group and both the MSC and HSC groups, nor between the MSC and HSC groups. Serum RF was lower in the MTX $(29.1 \pm 8.3 \mathrm{IU} / \mathrm{mL}), \mathrm{MSC}$ $(18.36 \pm 2.72 \mathrm{IU} / \mathrm{mL})$ and $\mathrm{HSC}(33.3 \pm 4.13 \mathrm{IU} / \mathrm{mL})$ groups compared to the PC group $(45.49 \pm 8.95 \mathrm{IU} / \mathrm{mL})$ with p-values $<0.0001,<0.0001$ and $<0.001$, respectively. The decrease in RF in the MSC group was significantly greater than in the MTX or HSC groups ( $p<0.001$ and $\mathrm{p}<0.0001$, respectively) (Fig. 2C).

Serum levels of IL- 6 , TNF- $\alpha$ and TGF- $\beta$ were decreased in the MTX group $(88.36 \pm 13.04,99.43 \pm 16.01$ 

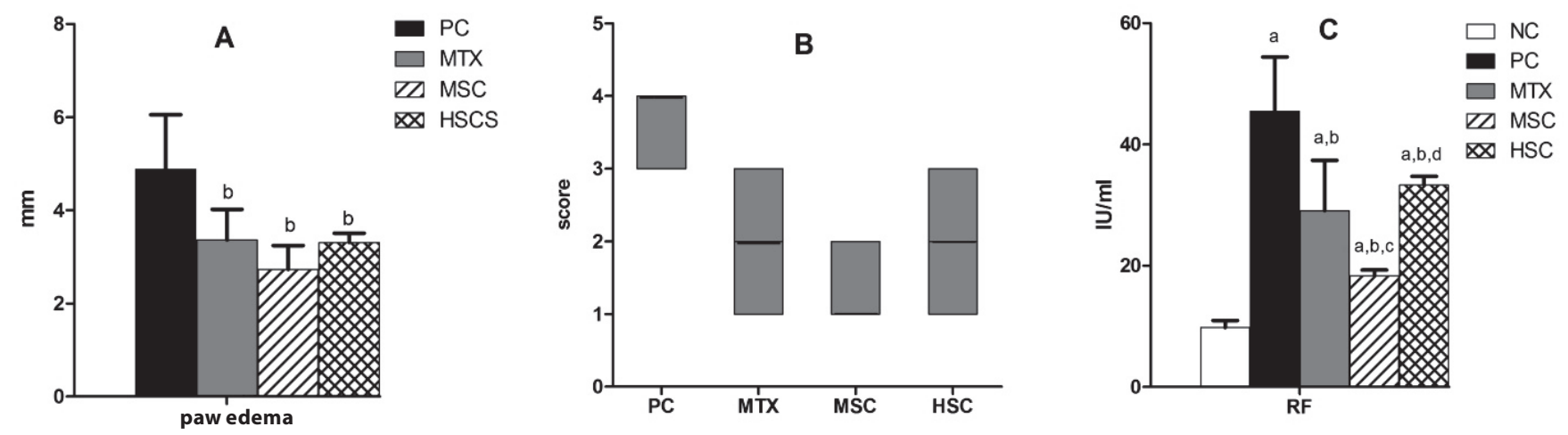

Fig. 2. The effects of different treatments on paw edema (A), RA score (B) and RF (C)

Parameters are presented on the charts as means $\pm \mathrm{SD}(\mathrm{A}, \mathrm{C})$ and as median and range (B); NC - negative control group; PC - positive control group; MTX - methotrexate group; MSC - mesenchymal stem cells group; HSC - hematopoietic stem cells group; a - significantly different from NC; $\mathrm{b}$ - significantly different from PC; $\mathrm{c}$ - significantly different from MTX; $d$ - significantly different from MSC.

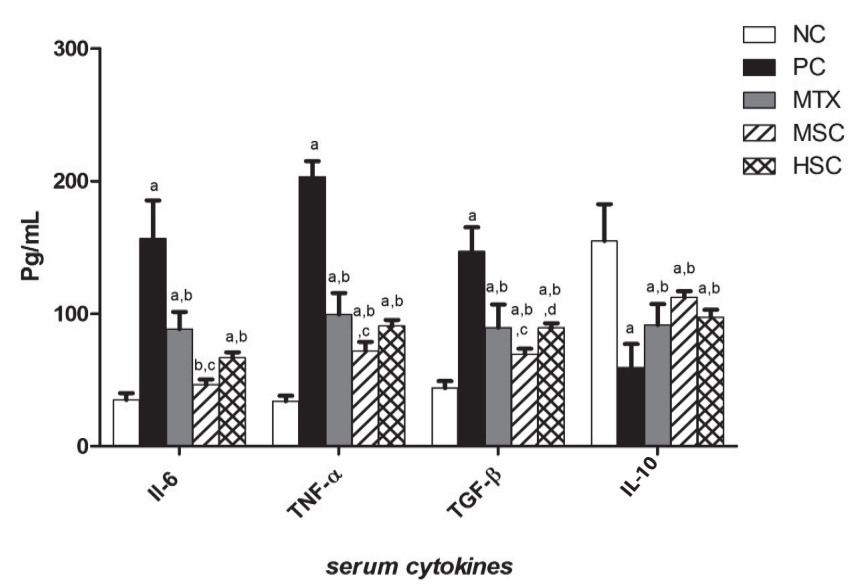

Fig. 3. The effects of different treatments on IL-6, TNF- $a, T G F-\beta$ and IL-10

Parameters are presented on the charts as means $\pm \mathrm{SD} ; \mathrm{NC}$ - negative control group; PC - positive control group; MTX - methotrexate group; MSC - mesenchymal stem cells group; HSC - hematopoietic stem cells group; IL-6 - interleukin-6; TNF-a - tumor necrosis factor-alpha; TGF- $\beta$ - transforming growth factor-beta; IL-10 - interleukin-10; a - significantly different from NC; b - significantly different from PC; $c$ - significantly different from MTX; d - significantly different from MSC.

and $89.53 \pm 17.34 \mathrm{Pg} / \mathrm{mL}$, respectively), the MSC group (46.38 $\pm 11.63,72 \pm 19.19$ and $69.19 \pm 12.38 \mathrm{Pg} / \mathrm{mL}$, respectively) and the HSC group $(66.83 \pm 11.24,90.75 \pm 12.73$ and $89.4 \pm 9.2 \mathrm{Pg} / \mathrm{mL}$, respectively) compared to the PC group $(156.6 \pm 28.74,203.3 \pm 11.73$ and $146.8 \pm 18.38 \mathrm{Pg} / \mathrm{mL}$, respectively) ( $<<0.0001)$. In the MSC group, IL- 6 and TNF- $\alpha$ were significantly lower than in the MTX group $(\mathrm{p}<0.0001$ and $\mathrm{p}<0.001$, respectively); there was no significant difference in IL-6 compared to the NC group $(34.93 \pm 5.1 \mathrm{Pg} / \mathrm{mL})$ ( $p>0.05)$. Furthermore, TGF- $\beta$ was lower in the MSC group than in the MTX and HSC groups $(\mathrm{p}<0.05)$. The 3 treated groups (MTX, MSCand HSC) showed elevated IL-10 levels in comparison to the PC group $(59.49 \pm 17.67 \mathrm{Pg} / \mathrm{mL})$ ( $\mathrm{p}<0.05, \mathrm{p}<0.0001$ and $\mathrm{p}<0.001$, respectively). Interleukin -10 was also elevated in the MSC group $(112.3 \pm 13.33 \mathrm{Pg} / \mathrm{mL})$ compared with the MTX $(91.44 \pm 15.83 \mathrm{Pg} / \mathrm{mL})$ and HSC

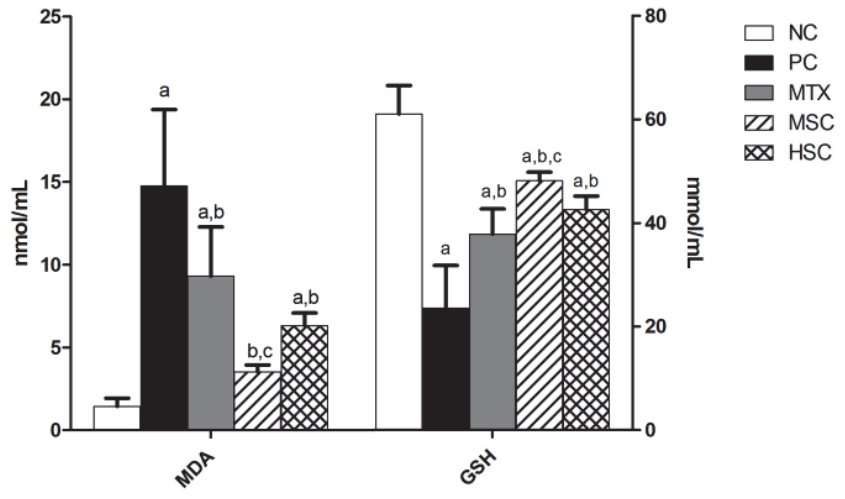

Fig. 4. The effects of different treatments on MDA and GSH

Parameters are presented on the charts as means $\pm \mathrm{SD}$; NC - negative control group; PC - positive control group; MTX - methotrexate group; MSC - mesenchymal stem cells group; HSC - hematopoietic stem cells group; MDA - malondialdehyde; GSH - reduced glutathione; a - significantly different from NC; $b$ - significantly different from PC; $c$ - significantly different from MTX; $d$ - significantly different from MSC.

(97.23 $\pm 16.36 \mathrm{Pg} / \mathrm{mL})$ groups, but this elevation was not significant (Fig. 3).

Malondialdehyde was significantly lower in the MTX $(9.33 \pm 2.96 \mathrm{nmol} / \mathrm{mL})$, MSC $(3.53 \pm 1.17 \mathrm{nmol} / \mathrm{mL})$ and HSC $(6.33 \pm 2.16 \mathrm{nmol} / \mathrm{mL})$ groups than in the PC group $(14.76 \pm 4.62 \mathrm{nmol} / \mathrm{mL})(\mathrm{p}<0.001, \mathrm{p}<0.0001$ and $\mathrm{p}<0.0001$, respectively); it was also significantly lower in the MSC group than in the MTX group ( $<<0.001)$. Glutathione was significantly higher in the MTX $(37.83 \pm 4.86 \mathrm{nmol} / \mathrm{mL})$, MSC (48.13 $\pm 4.76 \mathrm{nmol} / \mathrm{mL})$ and HSC (42.51 $\pm 7.45 \mathrm{nmol} /$ $\mathrm{mL})$ groups than in the PC group $(23.54 \pm 8.24 \mathrm{nmol} / \mathrm{mL})$ $(\mathrm{p}<0.0001)$, and in the MSC group than in the MTX group $(\mathrm{p}<0.05)$. There was no significant difference between the MSC group and the NC group $(1.45 \pm 0.49 \mathrm{nmol} / \mathrm{mL})$ with respect to MDA (Fig. 4).

The MSC group showed lower TLR-2, MMP-3 and $C O M P-1$ (relative quantification) $(2.47 \pm 0.39,2.72 \pm 1.04$ and $2.73 \pm 0.64$, respectively) than the PC $(13.35 \pm 1.65$, $13.34 \pm 3.7$ and $13.25 \pm 1.94$, respectively) and MTX 


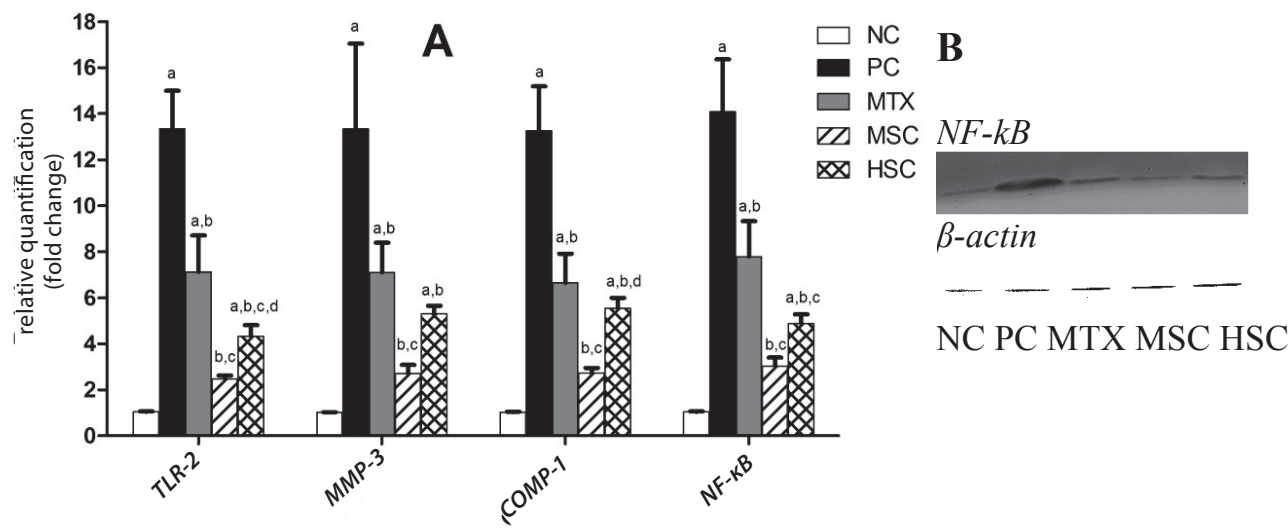

Fig. 5. The effects of different treatments on TLR-2, MMP-3, COMP-1 and NF-KB (A) and NF-KB protein blotting (B)

Parameters are presented on the charts as means \pm SD; NC - negative control group; PC - positive control group; MTX - methotrexate group; MSC - mesenchymal stem cells group; HSC - hematopoietic stem cells group; TLR-2 - toll-like receptor-2; MMP-3 - matrix metalloproteinase-3; COMP-1 - cartilage oligomeric matrix protein-1; NF-KB - nuclear factor-kappaB; $b$ - significantly different from PC; $c$ - significantly different from MTX; $d$ - significantly different from MSC.

(7.13 $\pm 1.6,7.11 \pm 1.28$ and $6.65 \pm 1.26$, respectively) groups $(\mathrm{p}<0.0001)$. Toll-like receptor-2 and COMP-1 were also significantly lower in the MSC group than in the HSC group (4.33 \pm 1.35 and $5.55 \pm 1.26$, respectively), with $\mathrm{p}$ values $<0.05$ and $<0.0001$, respectively. Toll-like receptor- 2 was significantly decreased in the HSC group in comparison to both the PC and MTX groups $(\mathrm{p}<0.0001)$, while $M M P-3$ and COMP-1 were only lower in the HSC group (5.3 \pm 0.99 and $5.55 \pm 1.26$, respectively) compared to the PC group ( $<$ 0.0001) (Fig. 5A). Nuclear factor-kappaB was significantly decreased in the 3 treated groups (MTX: $7.78 \pm 1.55$, MSC: $3.02 \pm 1.06$ and HSC: $4.88 \pm 1.15$ ), with the lowest value in the MSC group compared to the $\mathrm{PC}$ group $(1.04 \pm 0.07)(\mathrm{p}<0.0001)$. Nuclear factor-kappaB was lower in the MSC and HSC groups than in the MTX group, with p-values $<0.0001$ and $<0.001$, respectively (Fig. 5A, 5B).

\section{Discussion}

In the last 10 years, MSCs have drawn attention in the field of regenerative medicine because of their capacity to differentiate into specific cell types, their substantial production of soluble growth factors and cytokines and their hematopoiesis-supporting properties. Moreover, MSCs can move to areas of inflammation and exert potent immunomodulatory and anti-inflammatory actions by cell-to-cell interactions between MSCs and lymphocytes or by soluble factor production. Thus, it should be possible to use MSCs for future clinical treatment of several diseases. ${ }^{24}$

Mesenchymal stem cells are suggested by many studies to be highly immunosuppressive both in vivo and in vitro. They intensely inhibit the proliferation of many immune cells, such as T cells, B cells, dendritic cells and natural killer cells. Furthermore, some soluble factors such as TGF- $\beta$ and human growth factor (HGF) have been shown to play a role in the immunosuppressive actions of MSCs. This suggests that MSCs have the ability to treat immune disorders, prevent organ transplantation rejection and heal injured tissue. ${ }^{25}$

Various studies have been performed on MSCs originating from BM. Their transplantation from BM is assumed to be safe, and the results of their effects on neurological, cardiovascular and immunological diseases are hopeful. Mesenchymal stem cells have been found to enhance angiogenesis and have been used in the treatment of kidney, lung and muscle injuries as well as of chronic skin wounds. ${ }^{12}$

In RA, joint inflammation is caused by the infiltration of immune cells, synovial hyperproliferation, and the overproduction of proinflammatory cytokines, such as TNFo, IL-1 $\beta$, IL-6, IL-17 and IFN $\gamma$, finally causing cartilage and bone damage. ${ }^{26}$ The therapeutic effect of MSCs in collageninduced arthritis (CIA) might be related to the induction of regulatory T cells (Treg) by MSCs. ${ }^{27}$

In the current study, BM-derived MSCs were isolated, grown and characterized by CD29+ve, one of the surface markers of MSCs, and were used to investigate the role of MSCs, compared to HSCs (CD34+ve) and methotrexate, in the amelioration of arthritis in an experimental rat model, and to assess whether MSCs and HSCs could improve arthritis. We found that injecting MSCs into RA rats resulted in a rapid reversal of tissue inflammation. This drastic effect was accompanied by a diminished tissue level of IL-6, TNF- $\alpha$, TGF- $\beta$, NF- $\kappa B$, TLR-2, MMP-3, COMP-1, and $\mathrm{RF}$, a better antioxidant state and an elevated production of anti-inflammatory cytokine IL-10 in RA/MSC rats.

This concurs with the results published by Ganesan et al., who showed the ability of MSCs to suppress the immune system. ${ }^{28} \mathrm{~A}$ study by Augello et al. demonstrated that MSC injection stopped bone and cartilage damage and induced $\mathrm{T}$ cell hyporesponsiveness in the form of reduced proliferation and modified inflammatory cytokine 
expression; serum TNF- $\alpha$ levels in particular were significantly lowered. ${ }^{29}$

The ability of MSCs to inhibit the proliferation of stimulated T cells as well as TNF- $\alpha$ secretion was observed by Liu et al. ${ }^{30}$ The valuable effect of MSCs was proven by their attenuation of systemic inflammation, the reduction of proinflammatory cytokines (IL- 6 and TNF- $\alpha$ ) and an increased production of the anti-inflammatory cytokine IL-10 in CIA mice. After injecting CIA mice with MSCs, the severity of arthritis was significantly reduced. Moreover, MSC injection caused complete disappearance of paw swelling. ${ }^{31}$

Little is known about the mechanisms of the immunoregulatory activities of MSCs, but both direct and indirect effects have been proposed, through either cell-to-cell interaction or soluble factors. The immunosuppression of MSCs needs the MSCs to be activated first by immune cells via the secretion of some proinflammatory cytokines, such as IFN- $\gamma$, TNF- $\alpha$, IL- $1 \alpha$ or IL- $1 \beta .{ }^{32}$ Various studies done on BM MSCs have revealed that the immunomodulation effect mediated by MSCs depends on IFN- $\gamma$, and is primarily mediated by soluble factors, like indolamine 2,3-dioxygenase or prostaglandin E2 (PGE2), which inhibit the proliferation and function of both $\mathrm{T}$ and $\mathrm{B}$ cells. Prostaglandin E2 potentially suppresses the immune system through the inhibition of $\mathrm{T}$ cell mitogenesis and IL-2 production, and helps stimulate the activity of Th type 2 lymphocytes. The stimulation of TNF- $\alpha$ or IFN- $\gamma$ enhances the production of PGE2 by MSCs, which stimulates IL-10 production from the macrophages and blocks the differentiation of monocytes to dendritic cells. ${ }^{33}$

It has been reported that IL-6, another factor derived from MSCs, could inhibit monocyte differentiation to dendritic cells, decreasing their ability to stimulate T cells. Activated MSCs have been found to produce hepatocyte growth factor, heme oxygenase-1, leukemia inhibitory factor, and TGF- $\beta 1$. The cell-to-cell contact between MSCs and activated $\mathrm{T}$ cells prompts the production of IL-10, which participates in human leukocyte antigen (HLA)G5 release. The immunoregulation mediated by MSCs is therefore considered a sum of the collective activities of various molecules. ${ }^{34}$

Greish et al. reported that injecting stem cells (MSCs and HSCs) obtained from human UCB into CFA rats significantly decreased arthritis severity. ${ }^{35}$ They found that paw swelling had totally disappeared 21-34 days after stem cell administration. Moreover, they found a significant downregulation of TNF- $\alpha$, IL- 1 and IFN- $\gamma$, and the upregulation of IL-10 after the injection of HSCs and MSCs. ${ }^{35}$ Park et al. also found that MSCs significantly increased the levels of IL-10 and TGF- $\beta$, and decreased serum IL- $1 \beta$, TNF- $\alpha$, IL-6, and IFN- $\gamma{ }^{27}$

Mesenchymal stem cell licensing is related to the activation of TLRs expressed on the MSC surface. Mesenchymal stem cells are polarized toward either an inflammatory or an anti-inflammatory direction, depending on the TLR type. Toll-like receptor-4 (TLR-4) stimulation produces pro-inflammatory cytokines, such as IL-6, IL- 8 and TGF- $\beta$, developing the MSC1 phenotype. Conversely, when certain ligands bind to TLR-3, immunosuppressive MSC2 cells are stimulated to release indolamine 2,3-dioxygenase. ${ }^{36,37}$

El-denshary et al. reported that the expression of $M M P-3$, $C O M P$ and $T N F-\alpha$ genes was significantly reduced, while $I L-10$ gene expression was significantly increased in the MSC group compared to the CIA group. ${ }^{38}$ Their results indicated that MSCs were better than betamethasone in treating CIA, probably by modifying cytokine expression. Mesenchymal stem cells caused complete improvement in the oxidative stress environment in the form of lowered MDA and increased GSH.

In conclusion, MSCs are very effective in reducing RA inflammation and could become a better therapeutic opportunity for the treatment of RA.

\section{References}

1. Ikari K. Genetic risk factors for rheumatoid arthritis. Nihon Rinsho. 2016;74(6):897-901.

2. Innala L, Sjöberg C, Möller B, et al. Co-morbidity in patients with early rheumatoid arthritis - inflammation matters. Arthritis Res Ther. 2016;18:33. doi: 10.1186/s13075-016-0928-y

3. Choy E. Understanding the dynamics: Pathways involved in the pathogenesis of rheumatoid arthritis. Rheumatology (Oxford). 2012; 51(5):3-11.

4. Monaco C, Nanchahal J, Taylor P, et al. Anti-TNF therapy: Past, present and future. Int Immunol. 2015;27(1):55-62.

5. Gonzalo-Gil E, Galindo-Izquierdo M. Role of transforming growth factor-beta (TGF) beta in the physiopathology of rheumatoid arthritis. Reumatol Clin. 2014;10(3):174-179.

6. Simmonds RE, Foxwell BM. Signalling, inflammation and arthritis: NF-kappaB and its relevance to arthritis and inflammation. Rheumatology (Oxford). 2008;47(5):584-590.

7. Huang QQ, Pope RM. Role of toll like receptors in rheumatoid arthritis. Curr Rheumatol Rep. 2009;11(5):357-364.

8. Aref MI, Ahmed H. Cartilage oligomeric matrix protein as new marker in diagnosis of rheumatoid arthritis. Mod Chem Appl. 2015;3(2): 1000151. doi:10.4172/2329-6798.1000151

9. Acharya C, Yik JH, Kishore A, et al. Cartilage oligomeric matrix protein and its binding partners in the cartilage extracellular matrix: Interaction, regulation and role in chondrogenesis. Matrix Biol. 2014;37:102-111.

10. Smolen JS, Landewé R, Breedveld FC, et al. EULAR recommendations for the management of rheumatoid arthritis with synthetic and biological disease-modifying antirheumatic drugs: 2013 update. Ann Rheum Dis. 2014;73(3):492-509.

11. Singh JA, Saag KG, Bridges SL, et al. 2015 American College of Rheumatology Guideline for the Treatment of Rheumatoid Arthritis. Arthritis Care Res (Hoboken). 2016;68(1):1-25.

12. Malgieri A, Kantzari E, Patrizi MP, et al. Bone marrow and umbilical cord blood human mesenchymal stem cells: State of the art [published online ahead of print September 7, 2010]. Int J Clin Exp Med. 2010;3(4):248-269.

13. Sun L, Akiyama $K$, Zhang $H$, et al. Mesenchymal stem cell transplantation reverses multiorgan dysfunction in systemic lupus erythematosus mice and humans. Stem Cells. 2009;27:1421-1432.

14. Zippel N, Limbach CA, Ratajski N, et al. Purinergic receptors influence the differentiation of human mesenchymal stem cells. Stem Cells Dev. 2012;21(6):884-900.

15. Salem HK, Thiemermann C. Mesenchymal stromal cells: Current understanding and clinical status. Stem Cells. 2010;28(3):585-596.

16. Saeed H, Ahsan M, Saleem Z, et al. Mesenchymal stem cells (MSCs) as skeletal therapeutics - an update [published online ahead of print April 16, 2016]. J Biomed Sci. 2016;23:41. doi: 10.1186/s12929016-0254-3 
17. Borashan FA, Ilkhanipoor M, Hashemi M, et al. Investigation the effects of curcumin on serum hepatic enzymes activity in a rheumatoid arthritis model. eJBio. 2008;4(4):129-133.

18. Banji D, Pinnapureddy J, Banji OJ, et al. Synergistic activity of curcumin with methotrexate in ameliorating Freund's complete adjuvant-induced arthritis with reduced hepatotoxicity in experimental animals. Eur J Pharmacol. 2011;668(1-2):293-298.

19. Djouad F, Bony C, Haupl T, et al. Transcriptional profiles discriminate bone marrow-derived and synovium-derived mesenchymal stem cells. Arthritis Res Ther. 2005;7:1304-1315. doi: org/10.1186/ar1827

20. Zhao DC, Lei JX, Chen R, et al. Bone marrow derived mesenchymal stem cells protect against experimental liver fibrosis in rats. World J Gastroentrol. 2005;11(22):3431-3440.

21. Mohamed AO, Idriss NK, Sabry D, et al. Comparative study between the effects of human CD34 and rat bone marrow mesenchymal stem cells on amelioration of CCl4 induced liver fibrosis. EJB. 2015;33(1-2): 34-51.

22. Wills ED. Evaluation of lipid peroxidation in lipids and biological membranes. In: Snell K, Mullock B, eds. Biochemical Toxicology: A practical approach. Oxford \& Washington, DC: IRL Press; 1987:127-152.

23. Ellman GL. Tissue sulfhydryl groups. Arch of Bioch \& Biophys. 1959;82: 70-77.

24. Zhao Q, Ren $\mathrm{H}$, Han Z. Mesenchymal stem cells: Immunomodulatory capability and clinical potential in immune diseases. Journal of Cellular Immunotherapy. 2016;2(1):3-20.

25. Han Z, Jing Y, Zhang S, et al. The role of immunosuppression of mesenchymal stem cells in tissue repair and tumor growth. Cell Biosci. 2012;2(1):8. doi: 10.1186/2045-3701-2-8

26. Roberts CA, Dickinson AK, Taams LS. The interplay between monocytes/macrophages and CD4+ T cell subsets in rheumatoid arthritis. Front Immunol. 2015;6:571. doi: 10.3389/fimmu.2015.00571

27. Park $\mathrm{KH}$, Mun $\mathrm{CH}$, Kang Ml, et al. Treatment of collagen-induced arthritis using immune modulatory properties of human mesenchymal stem cells. Cell Transplant. 2016;25(6):1057-1072.
28. Ganesan K, Tiwari M, Balachandran C, et al. Estrogen and testosterone attenuate extracellular matrix loss in collagen-induced arthritis in rats. Calcif Tissue Int. 2008;83(5):354-364.

29. Augello A, Tasso R, Negrini SM, et al. Cell therapy using allogeneic bone marrow mesenchymal stem cells prevents tissue damage in collagen-induced arthritis. Arthritis Rheum. 2007;56(4):1175-1186.

30. Liu Y, Mu R, Wang S, et al. Therapeutic potential of human umbilical cord mesenchymal stem cells in the treatment of rheumatoid arthritis. Arthritis Res Ther. 2010;12(6):210. doi: 10.1186/ar3187

31. Mao F, Xu WR, Qian H, et al. Immunosuppressive effects of mesenchymal stem cells in collagen-induced mouse arthritis. Inflamm Res. 2010;59(3):219-225.

32. Ren G, Zhang L, Zhao X, et al. Mesenchymal stem cell-mediated immunosuppression occurs via concerted action of chemokines and nitric oxide. Cell Stem Cell. 2008;2:141-150.

33. Dazzi F, Krampera M. Mesenchymal stem cells and autoimmune diseases. Best Pract Res Clin Haematol. 2011;24(1):49-57.

34. Kang MI, Park Y. Immunomodulatory function of mesenchymal stem cells for rheumatoid arthritis. J Rheum Dis. 2016;23(5):279-287.

35. Greish S, Abogresha N, Abdel-Hady Z, et al. Human umbilical cord mesenchymal stem cells as treatment of adjuvant rheumatoid arthritis in a rat model. World J Stem Cells. 2012;4(10):101-109. doi: 10.4252/ wjsc.v4.i10.101

36. Romieu-Mourez R, Francois M, Boivin MN, et al. Cytokine modulation of TLR expression and activation in mesenchymal stromal cells leads to a proinflammatory phenotype. J Immunol. 2009;182: 7963-7973.

37. Waterman RS, Tomchuck SL, Henkle SL, et al. A new mesenchymal stem cell (MSC) paradigm: Polarization into a pro-inflammatory MSC1 or an immunosuppressive MSC2 phenotype. PLoS One. 2010;5(4): 10088. doi: 10.1371/journal.pone.0010088

38. El-denshary ESM, Rashed LA, Elhussiny M. Mesenchymal stromal cells versus betamethasone can dampen disease activity in the collagen arthritis mouse model. Clin Exp Med. 2014;14(3):285-295. 